\title{
Epilepsy trigger factors in Saudi Arabia
}

\author{
A missing part of the puzzle
}

Foziah J. Alshamrani, MD, Mohammed A. Alshurem, MD, Mohammed F. Almuaigel, MBBS, Noor M. AlMohish, MBBS.

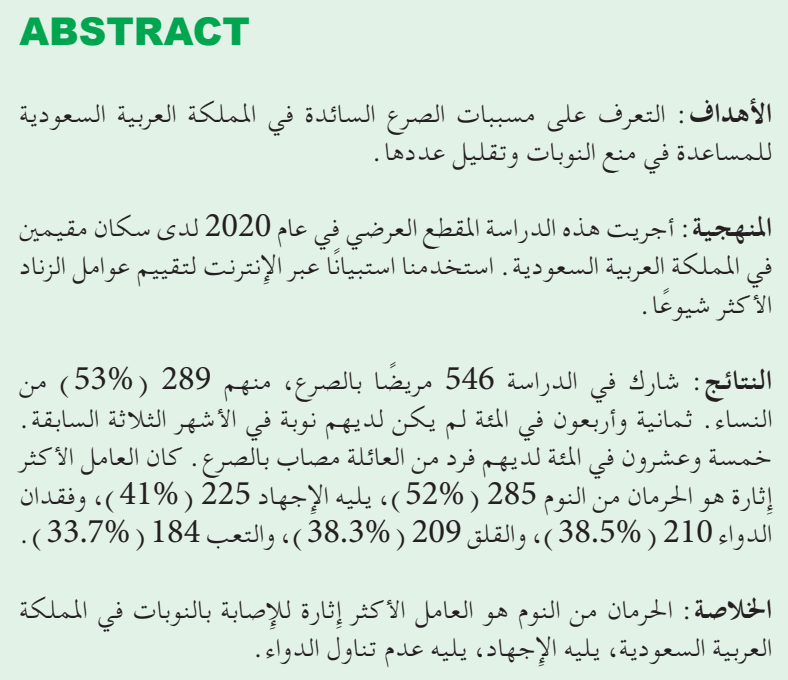

Objectives: To identify epilepsy triggers prevalent in Saudi Arabia with a view to seizure prevention or achieving a reduction in their frequency.

Methods: This is part of a cross-sectional study carried out in 2020 in a Saudi population in the Kingdom of Saudi Arabia (KSA). We used an online questionnaire to evaluate the most common seizure trigger factors.

Results: A total of 546 Saudi patients with epilepsy participated in the study, of which $289(53 \%)$ were women. Of them, 263 (48.1\%) had no seizure in the previous 3 months. One hundred and thirty-six $(25 \%)$ had a family member with epilepsy. The most-reported trigger factor was sleep deprivation reported by 285 ( $52 \%$ ), followed by stress 225 (41\%), missed medication $210(38.5 \%)$, anxiety $209(38.3 \%)$, and fatigue 184 $(33.7 \%)$.

Conclusions: Sleep deprivation is the most reported trigger factor for seizures in the KSA, followed by stress, followed by missed medication.

Keywords: epilepsy, trigger factor, Saudi Arabia, seizure

Saudi Med J 2020; Vol. 41 (8): 828-833 doi: $10.15537 /$ smj.2020.8.25220
From the Neurology Department (Alshamrani, Alshurem), College of Medicine Imam Abdulrahman Bin Faisal University, King Fahad University Hospital and from the Neurology Department (Almuaigel, AlMohish), King Fahad University Hospital, Al Khobar, Kingdom of Saudi Arabia.

Received 11th May 2020. Accepted 12th July 2020.

Address correspondence and reprint request to: Dr. Mohammed F. Almuaigel, Neurology Department, King Fahad University Hospital, Al Khobar, Kingdom of Saudi Arabia. E-mail: al.muaigel@hotmail.com ORCID ID: https://orcid.org/0000-0001-6161-8179

O ontortion is a neurologic confusion identified by an enduring tendency to seizures. ${ }^{1}$ A seizure is a sudden, transient brain dysfunction due to repeated, hypersynchronous discharge of central neurons. ${ }^{2}$ Epilepsy is a primary nervous system disease in which brain function fails to work, causing unusual behavior at times, loss of memorably, and sometimes sensations. ${ }^{3}$ In the Kingdom of Saudi Arabia (KSA), epilepsy occurs in 6.54 of 1000 individuals. ${ }^{4}$ The International League Against Epilepsy classifies seizures according to 2 systems: basic and expanded. ${ }^{5}$ Unusual behavior is classified according to the focal onset and restricted to one side of the brain hemisphere, or great start, with apparent clinical start in both hemispheres. ${ }^{6}$ The expanded unusual behavior Classification is for medical practitioners with extensive knowledge of epilepsy diagnosis and treatment. The skeleton is similar to that of the basic grouping, although particular subtopics are enlarging. Thus, brain-onset failure can carefully be classified depending on whether the first known distinct is, most significant activity, a neuromuscular activity that influences both sides of the patient's brain.

The goal of seizure management is freedom from seizures with no adverse effects of medication, and improvement in the quality of life of the patient. ${ }^{7}$ In a study by Sanya et $\mathrm{al}^{8}{ }^{8} 89 \%$ of the contender register more than one trigger for brain failure causing unusual behavior, and as many as 10 triggers were endorsed. 
Examples were stress, trauma, inadequate sleep, and culturally validated concepts such as demonic attacks and spells. However, common causal factors registered by patients were: missed medication $(40.9 \%)$, reaction stress (31.3\%), lack of fear (19.7\%), fatigue (15.3\%), skipped meals $(9.1 \%)$, fever (6.4\%), and smoking (6.1\%). The practical relationship was among commonly reported unusual behaviors (namely, skipped drugs subscription, sleep hardship, fatigue, and psychological stress).

Upon reviewing the literature, we found no data on trigger factors (TFs) for epilepsy in the KSA. This study is carried out to identify epilepsy triggers prevalent in Saudi Arabia, intending to prevent and mitigate seizures.

Methods. The research was based on a crosssectional of 2020 in a Saudi population in KSA. The university of Abdulrahman Bin Faisal accepted the Research procedure that was to be carried out ethically with regards to the ethical standards as was declared by Helsinki in 2020 review.

Between March 2020 and April 2020, we recruited male and female patients with epilepsy aged 18-50 years at an epilepsy clinic in the KSA.

To determine the most common TFs for seizures, we employed an online questionnaire incorporating the Delphi technique. We included only patients diagnosed with epilepsy (Figure 1). Preparing the survey, we tested the validity of each question in a pilot study with 10 participants, with an evaluation of the results by a panel of 4 experts. Issues with a reliability coefficient $>0.6$ were retained.

Statistical analysis. We used the Statistical Analysis for Social Sciences version 26 (Armonk, NY: IBM Corp). Descriptive analyses of sociodemographic characteristics are presented in a table using numbers and percentages. Data is analyzed descriptively using frequency and rates. The research uses the Pearson Chi-square and Fisher's exact tests' carry out the statistical examinations. The tool uses the formula, "A $p$-value $<0.05$ ". Based on "Qualtrics", sample-size calculator, 384 patients is the minimal number of epileptic patients should be recruited in the general population of KSA (which was $6.54 / 1000$ in 2009), ${ }^{9}$ and confidence intervals of $95 \%$ with a $5 \%$ margin of error.

Disclosure. Authors have no conflict of interests, and the work was not supported or funded by any drug company.
The data of each participant were coded and the data file secured by a password. For reasons of confidentiality, the study data are available only to the authors of this research.

Results. A total of 546 Saudi patients with epilepsy participated in this study. Fifty-three percent were female. The most frequent age group was 22-30 years $234(43 \%)$ of participants, followed by $18-21$ years 125 (23\%) of participants, and $31-40$ years 125 (23\%) of participants. Higher age groups were infrequent. Patients from all KSA provinces participated in this study; the highest percentage was from the Western area 145 $(26.6 \%)$ and the lowest was from the Northern region $45(8.2 \%)$. Approximately half of the participants had a university degree, while 158 (29\%) had a high school education, and other educational levels were infrequent (Table 1).

History taking showed that $263(48.1 \%)$ of participants had been seizure-free over the previous 3 months, $422(77.2 \%)$ were compliant with their treatment plan, and $136(24.9 \%)$ had a family member with epilepsy (Table 2).

The prevalence of participant comorbidities, risk factors, and possible etiologic disorders is presented in Table 3. The prevalence of smoking was $84(15.4 \%)$; alcohol use 14 (2.6\%); and drug abuse 15 (2.7\%). The most common comorbidity was asthma at $65(12 \%)$, followed by diabetes at $38(7 \%)$. The most common putative etiologic factors were head trauma at $71(13 \%)$ followed by prenatal hypoxia at $24(4.4 \%)$.

Figure 2 illustrates the TFs reported by the participants. The most-reported factor was sleep deprivation at $212(52 \%)$, followed by stress at 169 $(41 \%)$, missed medication at $160(38.5 \%)$, anxiety at $150(38.3 \%)$, and fatigue at $138(33.7 \%)$. The least reported factors were decreased coffee consumption, pregnancy, and eating a specific kind of food, each reported by less than $1 \%$ of participants.

In Table 4, the reported TFs are compared between patients with identified brain factors and those without seizures were idiopathic; applying the accurate Fisher's trial and that of Chi-squared. A higher percentage of participants with specific reasoning factors than those with idiopathic epilepsy reported the following TFs: fever, alcohol use, prolonged reading, studying for an examination, and an extended computer session lower percentage of participants with an etiologic factor than without reported hunger as a $\mathrm{TF}$.

Discussion. Several potential causes for epilepsy exist such as family history, brain pathology including 


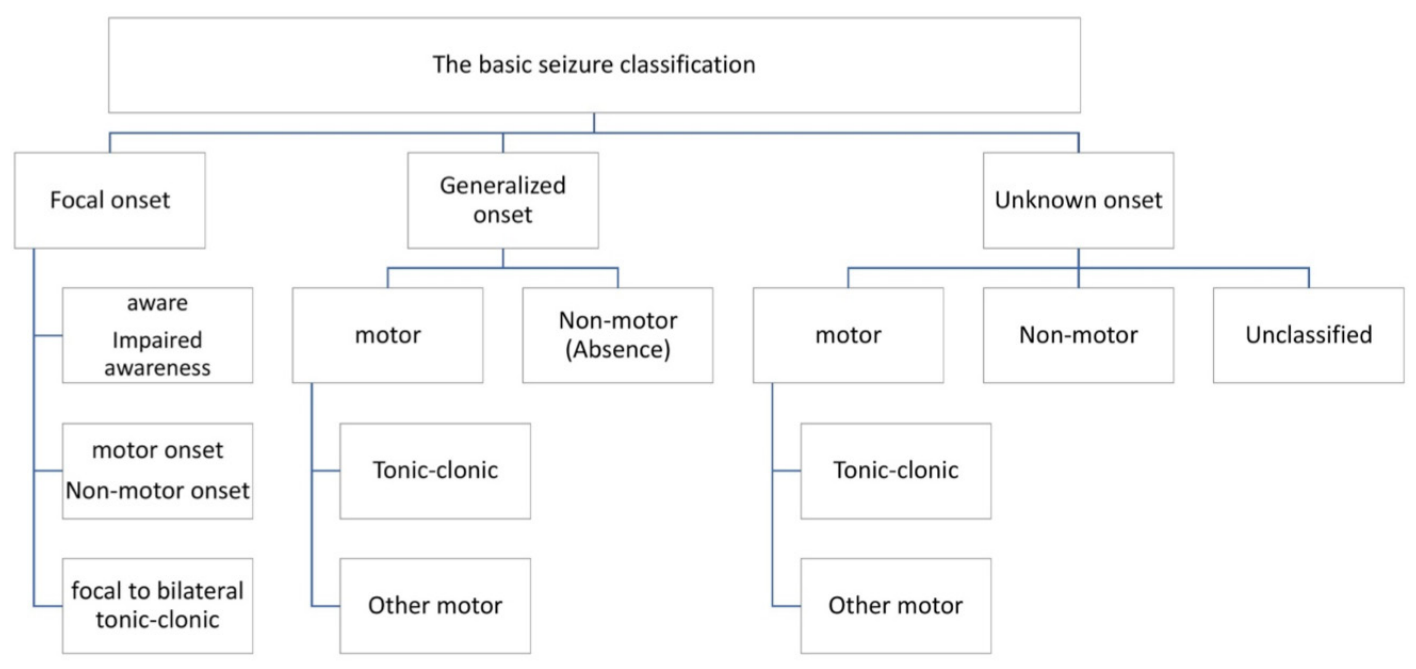

Figure 1 - The basic seizure classification.

Table 1 - Characteristics of participants.

\begin{tabular}{|c|c|c|}
\hline Characteristics & $\mathbf{n}$ & $(\%)$ \\
\hline \multicolumn{3}{|l|}{ Gender } \\
\hline Female & 289 & $(52.9)$ \\
\hline Male & 257 & $(47.1)$ \\
\hline \multicolumn{3}{|l|}{ Age } \\
\hline $18-21$ & 125 & $(22.9)$ \\
\hline $22-30$ & 234 & $(42.9) \mathrm{s}$ \\
\hline $31-40$ & 125 & $(22.9)$ \\
\hline $41-50$ & 44 & (8.1) \\
\hline$>50$ & 18 & (3.3) \\
\hline \multicolumn{3}{|l|}{ Region } \\
\hline Central province & 121 & $(22.2)$ \\
\hline Eastern province & 115 & $(21.1)$ \\
\hline Northern province & 45 & (8.2) \\
\hline Southern province & 120 & $(22.0)$ \\
\hline Western province & 145 & (26.6) \\
\hline \multicolumn{3}{|l|}{ Education } \\
\hline None & 22 & $(4.0)$ \\
\hline Primary & 20 & (3.7) \\
\hline Intermediate & 19 & $(3.5)$ \\
\hline High School & 158 & $(28.9)$ \\
\hline Bachelors & 307 & $(56.2)$ \\
\hline Master of Arts & 15 & (2.7) \\
\hline Doctor of Philosophy (PhD) & 5 & $(0.9)$ \\
\hline
\end{tabular}

Table 2 - Epilepsy history.

\begin{tabular}{|c|c|c|c|}
\hline History & $\begin{array}{c}\text { Women } \\
(\%)\end{array}$ & $\begin{array}{l}\text { Men } \\
(\%)\end{array}$ & $\begin{array}{l}\text { Total } \\
(\%)\end{array}$ \\
\hline \multicolumn{4}{|c|}{ Duration of illness (years) } \\
\hline Since childhood & $100(18.3)$ & $76(13.9)$ & $176(32.2)$ \\
\hline For the past $15-20$ & $47 \quad(8.6)$ & $57(10.4)$ & $104(19.0)$ \\
\hline For the past 10 & $41 \quad(7.5)$ & $41 \quad(7.5)$ & $82(15.0)$ \\
\hline For the past 5 & $101(18.4)$ & $83(15.2)$ & $184(33.7)$ \\
\hline \multicolumn{4}{|l|}{$\begin{array}{l}\text { Number of attacks per } \\
\text { month (last } 3 \text { months) }\end{array}$} \\
\hline None & $139(25.4)$ & $124(22.7)$ & $263(48.2)$ \\
\hline $1-3$ & $11(2.0)$ & $105(19.2)$ & $116(21.1)$ \\
\hline$>3$ & $39(7.1)$ & $28 \quad(5.1)$ & $67(12.3)$ \\
\hline \multicolumn{4}{|c|}{ Committed to treatment plan } \\
\hline No & $69(12.6)$ & $55(10.0)$ & $124(22.6)$ \\
\hline Yes & $220(40.2)$ & $202(36.9)$ & $422(77.3)$ \\
\hline \multicolumn{4}{|c|}{ Family history of epilepsy } \\
\hline No & $211(38.6)$ & $199(36.4)$ & $410(75.0)$ \\
\hline Yes & $78(14.2)$ & $58(10.6)$ & $136(24.9)$ \\
\hline \multicolumn{4}{|l|}{ Affected family member } \\
\hline First degree relative & $41(30.1)$ & $31(22.7)$ & $72(52.9)$ \\
\hline Second degree & $24(17.6)$ & $24(17.6)$ & $48(35.2)$ \\
\hline Third degree & $15(11.0)$ & $7(5.1)$ & $22(16.1)$ \\
\hline
\end{tabular}


Table 3 - Comorbidities, risk factors, and possible etiologic disorders.

\begin{tabular}{lrr}
\hline Comorbidities and risk factors & $\mathbf{n}$ & $(\%$ \\
\hline Smoker & 84 & $(15.4)$ \\
Alcoholic & 14 & $(2.6)$ \\
Drug abuser & 15 & $(2.7)$ \\
Asthma & 65 & $(11.9)$ \\
Thyroid disease & 30 & $(5.5)$ \\
Hypertension & 37 & $(6.8)$ \\
Diabetes mellitus & 38 & $(7.0)$ \\
Cardiac disease & 14 & $(2.6)$ \\
Stroke & 7 & $(1.3)$ \\
Metabolic disease & 3 & $(0.5)$ \\
Malignant disease & 9 & $(1.6)$ \\
Human immunodeficiency virus & 2 & $(0.4)$ \\
infection or acquired immune & & \\
deficiency syndrome & & \\
Autism & 10 & $(1.8)$ \\
Neurofibromatosis & 3 & $(0.5)$ \\
Possible etiologic disorders & & \\
Meningitis & 16 & $(2.9)$ \\
Brain tumor & 15 & $(2.7)$ \\
Head trauma & 71 & $(13.0)$ \\
Viral encephalitis & 2 & $(0.4)$ \\
Prenatal hypoxia & 24 & $(4.4)$ \\
Stroke & 7 & $(1.3)$ \\
Human immunodeficiency virus & 2 & $(0.4)$ \\
infection or acquired immune & & \\
deficiency syndrome & & \\
\hline & & \\
\hline
\end{tabular}

vascular and space occupying lesions and trauma. And multiple TFs described by previous studies, it is difficult sometimes for the patients to determine the exact TF for the seizure. Combination of more than one TF can exist. This study achieved our aim of identifying the common TFs for epilepsy in the KSA, which was carried out as a self-administered survey which could be a limitation compared to the usual seizure diaries and long-term monitoring. Earlier studies have focused on seizure TFs but not in the KSA. The present research fills this gap in the literature. We tried to limit the misunderstandings of some of the questions and carried a risk of subjectivity in the answers given by doing a pilot study in 10 participants. The reliability coefficient was found to be $>0.6$, which confirmed that the questionnaire was suitable for use in this study.

In the present study, TF associated with oversleeping has been reported on many occasions. In a study of 71 patients, Haut et al found that seizure conditions are associated with much anxiety, oversleeping and depression. ${ }^{10}$ A survey by Sanya et al, ${ }^{8} 27$ participants (30\%) mentioned inadequate sleep as the TF for their first seizure. In the present study, 258 patients (52.2\%) reported a history of seizure after sleep deprivation. This has an importance for more sleep hygiene for better seizure control.

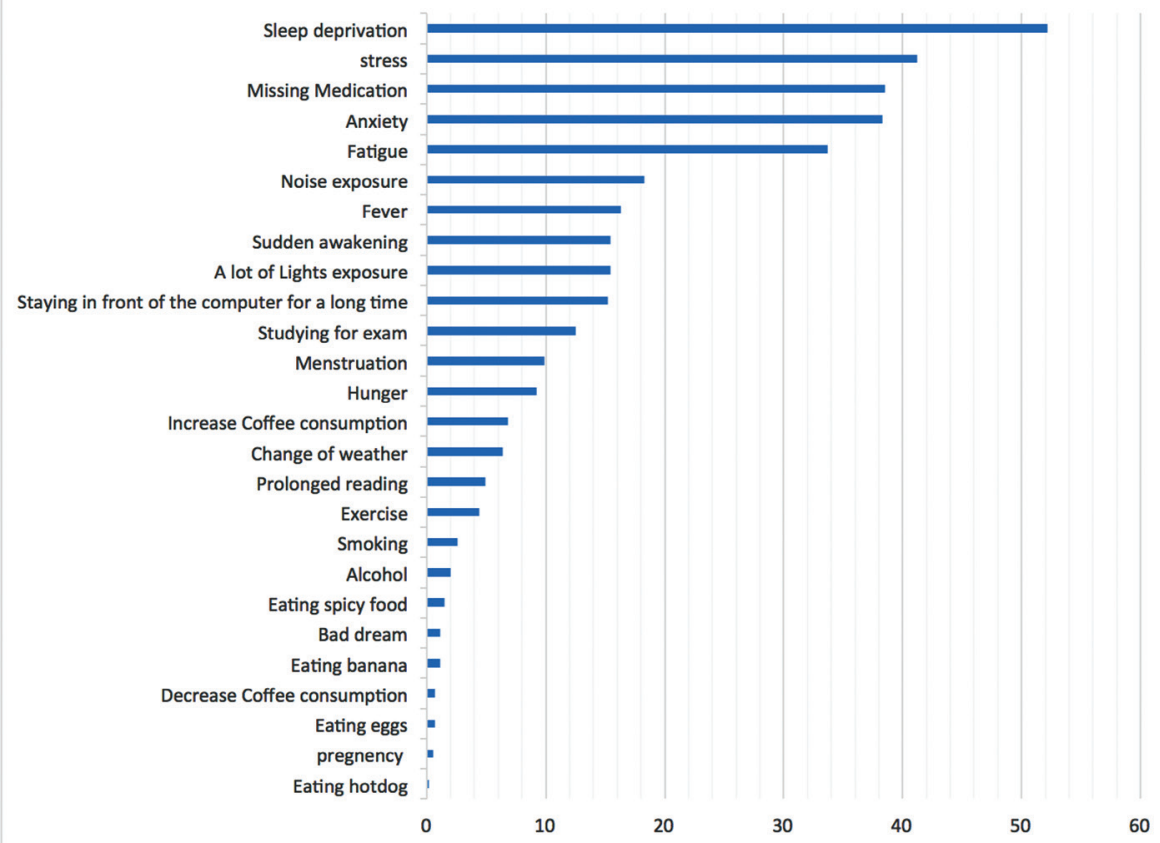

Figure 2 - Triggering factors as percentage reported by participants. 
Table 4 - Epilepsy triggers versus etiological status.

\begin{tabular}{|c|c|c|c|c|}
\hline \multirow[t]{2}{*}{ Triggering factors } & \multicolumn{2}{|c|}{ Etiology } & \multirow[t]{2}{*}{ Total } & \multirow[t]{2}{*}{ P-value } \\
\hline & $\begin{array}{l}\text { Idiopathic (no } \\
\text { specific etiology) }\end{array}$ & $\begin{array}{l}\text { Having an etiologic } \\
\text { factor }\end{array}$ & & \\
\hline Stress & $169(41.8)$ & $56(39.4)$ & $225(41.2)$ & 0.618 \\
\hline Anxiety & $150(37.1)$ & $59(41.5)$ & $209(38.3)$ & 0.351 \\
\hline Flashing light & $57(14.1)$ & $27(19.0)$ & $84(15.4)$ & 0.163 \\
\hline Noise & $74(18.3)$ & $26(18.3)$ & $100(18.3)$ & 0.999 \\
\hline Sleep deprivation & $212(52.5)$ & $73(51.4)$ & $285(52.2)$ & 0.827 \\
\hline Fatigue & $138(34.2)$ & $46(32.4)$ & $184(33.7)$ & 0.702 \\
\hline Fever & $55(13.6)$ & $34(23.9)$ & $89(16.3)$ & $0.004^{*}$ \\
\hline Exercise & $16(4.0)$ & $8 \quad(5.6)$ & $24 \quad(4.4)$ & 0.403 \\
\hline Missed medication & $160(39.6)$ & $50(35.2)$ & $210(38.5)$ & 0.355 \\
\hline Hunger & $44(10.9)$ & $6 \quad(4.2)$ & $50 \quad(9.2)$ & $0.018^{*}$ \\
\hline Sudden awakening & $65(16.1)$ & $19(13.4)$ & $84(15.4)$ & 0.442 \\
\hline Smoking & $7 \quad(1.7)$ & $7 \quad(4.9)$ & $14 \quad(2.6)$ & 0.058 \\
\hline Bad dream & $3(0.7)$ & $3(2.1)$ & $6(1.1)$ & 0.185 \\
\hline Change of weather & $26 \quad(6.4)$ & $9 \quad(6.3)$ & $35 \quad(6.4)$ & 0.967 \\
\hline Alcohol & $5(1.2)$ & $6 \quad(4.2)$ & $11 \quad(2.0)$ & $0.040^{*}$ \\
\hline Pregnancy & $2(0.5)$ & $1 \quad(0.7)$ & $3(0.5)$ & 1.000 \\
\hline Menstruation & $45(11.1)$ & $9 \quad(6.3)$ & $54 \quad(9.9)$ & 0.099 \\
\hline Decreased coffee consumption & $3(0.7)$ & $1 \quad(0.7)$ & $4 \quad(0.7)$ & 1.000 \\
\hline Increased coffee consumption & $26(6.4)$ & $11 \quad(7.7)$ & $37 \quad(6.8)$ & 0.593 \\
\hline Prolonged reading & $15 \quad(3.7)$ & $12(8.5)$ & $27 \quad(4.9)$ & $0.025^{*}$ \\
\hline Studying for exam & $40 \quad(9.9)$ & $28(19.7)$ & $68(12.5)$ & $0.002^{*}$ \\
\hline Prolonged computer session & $54(13.4)$ & $29(20.4)$ & $83(15.2)$ & $0.044^{*}$ \\
\hline Eating spicy food & $6(1.5)$ & $2(1.4)$ & $8(1.5)$ & 1.000 \\
\hline Eating banana & $4(1.0)$ & $2(1.4)$ & $6(1.1)$ & 0.653 \\
\hline Eating hotdog & $\begin{array}{ll}0 & (0.0)\end{array}$ & $1 \quad(0.7)$ & $1 \quad(0.2)$ & 0.260 \\
\hline Eating eggs & $1 \quad(0.2)$ & $3(2.1)$ & $4(0.7)$ & 0.056 \\
\hline
\end{tabular}

Depression came the second-highest TF followed by stress and AED noncompliance, a combination of 2 or more TFs were founded. A similar result was seen in this study which was comparable with a study of 266 patients carried out by Privitera et $\mathrm{al}^{11}$ reported that depression that is caused by seizures can be related to chronic or acute sadness and may be associated with an increase of anxiety tests. Exercise is one stress reduction mechanism that most patients with depressed condition often employ for them to come out of such situations. However, in a study of 100 patients, Neufeld et al ${ }^{12}$ found that acute external emotions are the contributors to the epilepsy control. However, Thapar et $\mathrm{al}^{13}$ concluded that anxiety predicts changes in seizure recurrence. In the present study, 225 patients (41.2\%) described a history of seizure after stress. The level of psychological stress should be measured in future articles. Stress itself can lead to sleep deprivation and fatigue and make it difficult to determine which factor was the attributed to the seizure episode. In a study of 1677 patients, Nakken et $\mathrm{al}^{14}$ found that those with generalized epilepsy more commonly reported flashing lights as a TF than those with localized forms of epilepsy. However, in a study of 400 patients by Frucht et al, ${ }^{15}$ only $4 \%$ noted seizures induced by flashing lights. In our study, 84 patients 
(15.4\%) had a history of seizure upon exposure to flashing lights.

Balamurugan et $\mathrm{al}^{16}$ and Jallon et $\mathrm{al}^{17}$ reported that emotional stressors might initiate epileptic seizures, especially when combined with fatigue and chronic sleep deficit. In our study, 184 patients (33.7\%) described a history of seizure after exhaustion. Cross ${ }^{18}$ states that following febrile seizures, other seizure types may develop promptly as a direct result. In different scenarios, an epilepsy syndrome develops with a delay after the occurrence of febrile seizures. In the present study, 89 patients $(16.3 \%)$ described a history of seizure after fever. Loud sound can be one of the TFs of reflex epilepsy. Ozer et $\mathrm{al}^{19}$ found that this type of seizure is mostly seen in elderly patients known to have epilepsy. In our study, 100 patients (18.3\%) described a history of seizure after noise exposure.

This study did help to increase the awareness of the patients to the possible TF of their seizure and try to avoid them and more seizure control. Prospective studies may clarify the relationship between these seizure TFs and their mechanisms to predispose seizures.

In conclusions, the present study designed to identify abnormal functioning of brain triggers prevalent in the KSA with a view to seizure prevention or a reduction in their frequency. Sleep deprivation was the most reported $\mathrm{TF}$, followed by stress, then missed medication.

Acknowledgment. We would like to acknowledge Abdulaziz H. Haddad, Asim H. Alrashid, Fares $H$. Alghamdi, Abdullah M. Alaithan, Rakan FM Almutairi, Mohammed N. Al-Mulhim, Ali M. Al aithan, Hassan A. Mejamemi, Rayyan F. Altemani, Wejdan K. Suwayyid, Albatool W. Gotah, Nujud A. Albalawi, Farah K. Alhamidy, Raghad S. Aljuaid, Heetaf A. Saeed, Hend O. Almerdas, Tajih M. Alaithan, Lena M. Al Mutairi, Afnan M. Alsaad, Hanadi M. AlGarni, Amna A. Alhilali, Bshayer A. Alsaleh, and Raneem M. Almuaikel for data collection. We are grateful and appreciate Editage (www.editage.com) for the English language editing.

\section{References}

1. Nasir BB, Berha AB, Gebrewold MA, Yifru YM, Engidawork E, Woldu MA. Drug therapy problems and treatment satisfaction among ambulatory patients with epilepsy in a specialized hospital in Ethiopia. PloS One 2020; 15; e0227359.

2. Duan L, Lian Z, Chen J, Qiao Y, Miao J, Li M. Classification of epilepsy period based on combination feature extraction methods and spiking swarm intelligent optimization algorithm. Concurr Comp-Pract E 2020: e5550.
3. Fisher RS, Acevedo C, Arzimanoglou A, Bogacz A, Cross JH, Elger CE, et al. ILAE official report: a practical clinical definition of epilepsy. Epilepsia 2014; 55: 475-482.

4. Pottoo FH, Alshayban DM, Joseph R, Al-Musa F, Al-Jabran O, Aljaafari D. Impact of adherence to antiepileptic medications on quality of life of epileptic patients in the Eastern Province of Saudi Arabia: A cross-sectional study. Imam J Appl Sci 2020; 5: 1.

5. Fisher RS, Cross JH, French JA, Higurashi N, Hirsch E, Jansen FE, et al. Operational classification of seizure types by the International League Against Epilepsy: Position Paper of the ILAE Commission for Classification and Terminology. Epilepsia 2017; 58: 522-530.

6. Fisher RS. The new classification of seizures by the International League Against Epilepsy 2017. Curr Neurol Neurosci Rep 2017; 17: 48.

7. Uijl SG, Uiterwaal CS, Aldenkamp AP, Carpay JA, Doelman JC, Keizer K, et al. Adjustment of treatment increases quality of life in patients with epilepsy: a randomized controlled pragmatic trial. Eur J Neurol 2009; 16: 1173-1177.

8. Sanya EO, Mustapha K, Ademiloyi A, Bello A, Alaofin O. Self-perceived seizure precipitants among patients with epilepsy in middle-belt Nigeria. Niger J Clin Pract 2014; 17: 701-705.

9. Benamer HTS, Grosset DG. (2009). A systematic review of the epidemiology of epilepsy in Arab countries. Epilepsia 2009; 50: 2301-2304.

10. Haut SR, Hall CB, Masur J, Lipton RB. Seizure occurrence: precipitants and prediction. Neurology 2007; 69: 1905-1910.

11. Privitera M, Walters M, Lee I, Polak E, Fleck A, Schwieterman $D$, et al. Characteristics of people with self-reported stressprecipitated seizures. Epilepsy Behav 2014; 41: 74-77.

12. Neufeld MY, Sadeh M, Cohn DF, Korczyn AD. Stress and epilepsy: the Gulf war experience. Seizure 1994; 3: 135-139.

13. Thapar A, Kerr M, Harold G. Stress, anxiety, depression, and epilepsy: investigating the relationship between psychological factors and seizures. Epilepsy Behav 2009; 14: 134-140.

14. Nakken KO, Solaas MH, Kjeldsen MJ, Friis ML, Pellock JM, Corey LA. Which seizure-precipitating factors do patients with epilepsy most frequently report? Epilepsy Behav 2005; 6: 85-89.

15. Frucht MM, Quigg M, Schwaner C, Fountain NB. Distribution of seizure precipitants among epilepsy syndromes. Epilepsia 2000; 41: 1534-1539.

16. Balamurugan E, Aggarwal M, Lamba A, Dang N, Tripathi M. Perceived trigger factors of seizures in persons with epilepsy. Seizure 2013; 22: 743-747.

17. Jallon P, Zifkin BG. In: Engel J, Pedley TA, Aicardi J, editors. Epilepsy: a comprehensive textbook. Lippincott Williams \& Wilkins; 2008.

18. Cross JH. Fever and fever related epilepsies. Epilepsia 2012; 53: 3-8.

19. Ozer F, Mutlu A, Ozkayran T. Reflex epilepsy and non-ketotic hyperglycemia. Epileptic Disord 2003; 5: 165-168. 